\title{
Tools of distance learning educational process at an Engineering University
}

\author{
L. Maksimenko ${ }^{1, *}, O$. Korobova $^{2}, V$. Kalyuzhin $^{1}, N$. Ivantcivskaya ${ }^{3}$, and $I$. Makarikhina $^{2}$ \\ ${ }^{1}$ Siberian State University of Geosystems and Technologies, 10 Plakhotnogo, 630000, Novosibirsk, \\ Russia \\ ${ }^{2}$ Novosibirsk State University of Architecture and Civil Engineering (Sibstrin), Novosibirsk, 630008 \\ Russia \\ ${ }^{3}$ Novosibirsk State Technical University, 20 Marx Ave, Novosibirsk, 630000, Russia
}

\begin{abstract}
The article discusses ways to organize the work of students and teachers in remote work mode. The high efficiency of the point-rating system (PRS) for evaluating independent work in the conditions of distance learning is shown. A study was conducted on the preparation of training and monitoring activities for online classes. The issues of organizing lectures and laboratory classes, as well as conducting training practice during the period of remote work are considered. Internet opens up wide opportunities in the process of electronic textbooks on humanitarian disciplines creating. The technologies' specifics allow making direct links to resources located in the worldwide network. Many experts believe that Internet technology is a revolutionary breakthrough, surpassing the importance of a personal computer appearance. Currently, there is a significant increase in the share of test passing in remote mode. For the development of electronic tests, there are many software tools that allow you to develop them according to a teacher preference. The important selection criteria are accessibility, the ease of use, the absence of any additional knowledge and skills, as well as the utmost clarity and comprehensibility of the proposed actions
\end{abstract}

\section{Introduction}

The highlighted era of distance education has already been said about. It's time -period has already come. The past period of forced remote work has shown that distance learning has its own methods and laws, and even a small accumulated experience of teaching a particular discipline online deserves attention and public coverage. In accordance with clauses 1.2 and 1.3 of the Ministry of Education of the Russian Federation Order, dated March 17, 2020 No. 104: - contact work of students and teaching staff is carried out exclusively in the electronic information educational environment; - the interaction of students and teaching staff is provided indirectly (at a distance) through the use of distance learning technologies; - the implementation of additional professional programs is almost provided. E-learning introduction into the educational process is enshrined in the Federal

\footnotetext{
*Corresponding author: maksimenko la@mail.ru
} 
Law "On Education in the Russian Federation" (dated December 29, 2012 No. 273-FZ) and in the order of the Ministry of Education and Science of the Russian Federation No. 816, dated August 23, 2017 "On Approval of the Procedure for Application by Organizations, carrying out educational activities, e-learning, distance educational technologies in the implementation of educational programs."

At present, the electronic educational environment is actively developing and is distinguished by a great variety both within university developments and educational platforms with a developed service of educational resources, which presents participants of educational process to reproduce all actions of the offline process online. The design and content of digital educational resources is very diverse. As a common component, one feature can be distinguished - the availability of open information and educational resources available to all visitors and closed corporate resources available to employees and students.

An alternative educational model for universities and organizations that combined project activities, transition to individual educational trajectories and building a digital profile was created by the University at 20.35 , where recommendation systems were developed and provided for personal development throughout life, using all educational opportunities [1]. The educational platform Urayt has a special status. This resource turned out to be a unique assistant in conducting distance learning for many teachers in the country, during the period of the forced massive transition to distance learning. The following aspects were provided for free use: electronic libraries of textbooks by teachers of leading universities for all levels of professional education, video and audio materials, tests and services for teachers [2].

\section{Virtual labs and computer simulators}

\subsection{Learning environment}

Modern methods of communication and data exchange make it possible to create and apply new methods in teaching, namely electronic web resources, tests, glossaries, polls, video conferencing, chats and other free software systems.

The possibility of using electronic methods is implemented in the Moodle learning environment [3]. An example of a Russian educational platform is the constructor of free open online courses by Stepik. Discord is used as a proprietary free messenger with support for VoIP, video conferencing and other capabilities in order to organize the educational process, [4].

Virtual laboratory complexes and computer simulators may be the most effective in distance learning. For example, virtual educational complexes for geodesy give an idea of how to build and analyze terrain, study a structure and principle of operation, as well as methods of operating geodetic instruments; to measure the parameters of the territory using geodetic instruments, to study the satellite navigation systems GPS, etc. [5].

The virtual laboratory "Building materials science" has been used in the educational process for several years. The software product is designed to simulate laboratory work in the course of building materials science. The program simulates technical devices and classical laboratory installations of building materials. The laboratory works are performed in the form of three-dimensional modules, which allow participating in a physical experiment to determine the properties of building materials with a high degree of reality [6].

For distance learning, the developments of the Autodesk Corporation are widely used [7]. Among them are Autodesk Revit Architecture programs, AutoCAD Architecture 
building design applications, AutoCAD Civil 3D and AutoCAD MAP, Autodesk InfraWorks, etc.

\subsection{Distance learning tools}

The choice of a software product for organizing video conferencing with students and transmitting content in real time during the period of remote access was influenced by the methodological instructions of educational organization, availability of software product in the free version, teacher's personal preferences, and other factors. The most popular solutions were Zoom [8], Microsoft Teams [9] and others.

Online learning presupposes certain rules for conducting a lesson. A clear structuring of the lesson and certain rules are required. They are communicated to the participants in advance: the order of turning on / off microphones and video, chat support for feedback, if necessary, video recording. The digital format of the lectures and practical classes led to the use of software products such as menti.com, pollev.com, wooclap.com for surveys and micro-assignments; nowcomment.com, perusal.com for digital engagement, Canva: online presentation service, and more.

The most difficult was the online exam. A lot of preparatory work was done to conduct the exam in a remote format. A schedule was drawn up for the examination session, the format of the exam and proctoring was determined. The distribution of roles was also important: a moderator was chosen among the students, who determine the order of joining the exam. Several exam formats have been tried already.

\subsection{Organization of the practice}

The Department of Geomatics and Real Estate Infrastructure organizes and conducts summer training practices in geodesy in the first and second year for students in the field of "Land management and cadastres". The task arose, switching to distance learning: how to adapt the programs of the above practices to a remote mode.

As you know, competence -oriented tasks are closely interconnected with the technology and methodology of the educational process [10]. Therefore, it is necessary to develop a model and technology for the formation of professional competencies in students that determine their readiness and ability, as future specialists, to effectively use knowledge, skills and abilities in processing measurement results and drawing up digital topographic plans using modern applied programs and geoinformation technologies.

As a rule, submodel of education is understood as a model that reflects certain ideas about the organization of the educational process as a whole. Currently, all models of education can be divided into two large classes: traditional and innovative, and according to the type of organization, they are divided into: state-departmental organizations; developmental education (V. V. Davydov, V. V. Rubtsov, etc.); systematic academic education (J. Majot, L. Cro, D. Ravich and others); rationalistic (P. Bloom, R. Gagne and others); phenomenological (A. Maslow, A. Combs, K. Rogers, etc.) and non-institutional (P. Goodman, I. Illich, F. Klein, etc.). It is advisable to use an innovative model as a conceptual one, and rationalistic one. The knowledge and experience, gained with such a model of education, allows an individual to enter the system of social relations and occupy a niche in it in the professional sphere and in life.

It is necessary to focus on the processing of topographic and geodetic information, including the preparation and execution of a topographic plan in the process of selecting the educational practice content. 
So for the first course, you should use analog technology in geodesy, and for the second - mainly digital. For planned classes and independent work of students, it is necessary to use a combined method that combines traditional and innovative methods.

Independent students work involves a wide variety of forms: from performing simple tasks to completing a project in a group (brigade).

The activation of the process within the practice-oriented technology of the professional competencies formation is facilitated by all types of teacher-student communications: frontal, group and individual. At the same time, you can use a wide range of computer technologies: from messenger and e-mail to video conferencing on platforms: Zoom, Skype, MeetJit, Teams, etc.

It is important to choose the best methods, types and forms of control over the educational activities' results and the formation of professional competencies, organizing the learning process. So, it is necessary to provide a control and evaluation component. It is advisable to use the following types of control: current, intermediate and final. Current control is carried out in the form of a frontal survey and testing and in a set of practical tasks form for intermediate and final ones.

The Department has developed the technology of educational practices, based on the developed model. In a generalized form, it consists of seven stages: preparatory; verification and research of geodetic instruments; processing altitude justification; processing of planned justification; processing of tacheometric survey results and design of the topographic plan; report preparation; passing the test.

At the first stage, the following quasi-professional situation was determined: either each student or a team of students consisting of 5 people is a desk group, which purpose is to create a topographic plan on paper for first-year students, and a digital topographic plan, using modern geodetic instruments, systems and special applied software (Credo-Dat 5.0), geoinformation system (MapInfo) for the second one.

For the chosen quasi-professional situation, the initial materials were prepared: schemes and measurement journals. Here, we used student reports from the last five years. Then each team or student was assigned a goal, objectives, and source materials.

At the second stage, the trainees described verification and research of devices and accessories that were used in the measurements.

At the third and fourth stages, the students processed the measurement results, creating a geodetic justification. The result was a traverse scheme and a catalog of coordinates and heights.

At the fifth stage, the students created a topographic plan on a scale of 1: 500 .

During the second-fifth stages, current and intermediate controls were carried out. After the report completing, the student passed the test.

If the work was carried out by the team, a teacher and students carried out reflection: they evaluated the activities of each student during the test. Here the teacher, together with the students, discussed the performance assessment of each and collectively work and made the final decision.

\section{Results}

The navigation system of the electronic textbook provides direct transitions from any module or block to the main page of "bookmarks" system (navigator, theory, examples, tasks, questions, tests, thesaurus), any transitions between blocks of one module, and forward and backward through already viewed frames sequence Figure1. 


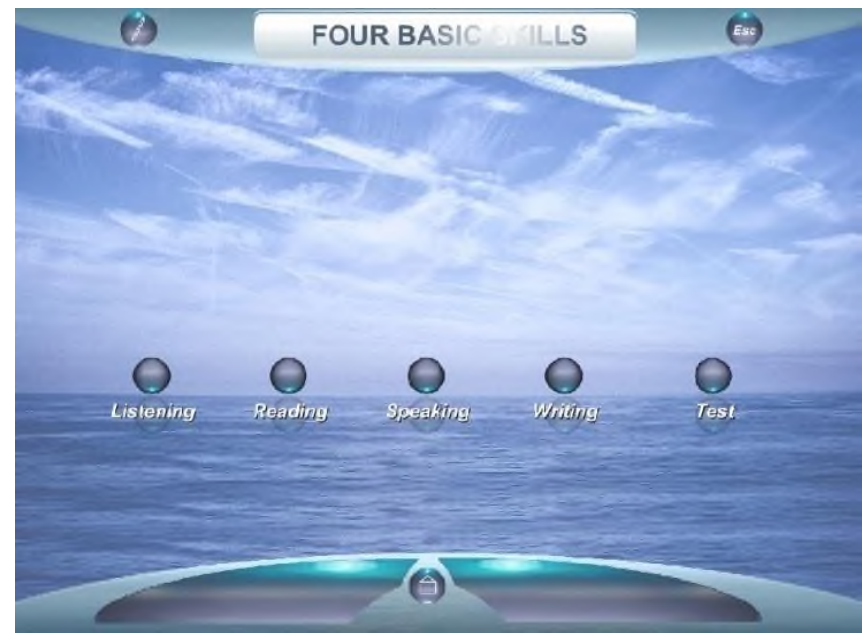

Fig. 1. Structure of the course.

Electronic textbooks on humanitarian disciplines differ in the features of these disciplines studying, which require a large amount of visual material. The problem of providing humanitarian disciplines with visual material can be partially solved with the help of multimedia [11-12]. Visual material can be presented both in the form of separate illustrative tables, graphic schemes supplementing the educational text, and with the help of slides, video films illustrating theoretical material Figure2.

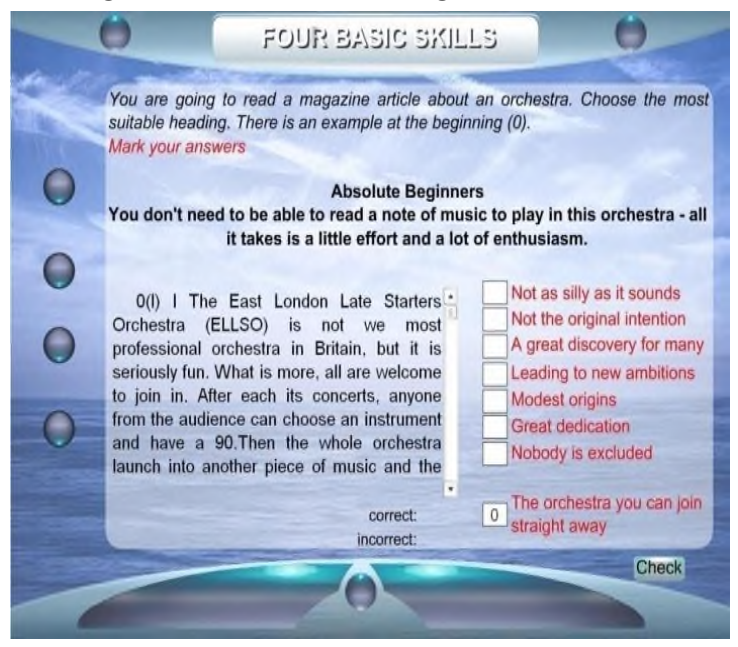

Fig. 2. Computer testing system as part of an electronic textbook.

The electronic special course "Didactic preparation of a foreign language teachers " contains multimedia structured lectures, interactive practical assignments, tests [14- 15].

\subsection{Point-rating system for assessing work in the context of distance education}

As practice has already shown, the use of knowledge point-rating assessment is very effective for conducting classes with remote access. The authors have accumulated experience in applying a similar technique. The main stages of work in this case are: preparation of a work schedule, systematic and timely tracking of work performance, 
current control, final control, communicating the results of the rating to students [13]. Evaluation of works is carried out in points recalculated into the traditional assessment: from 50 to 73 points the mark is given - satisfactory; 74 - 85 points - assessment - good; more than 85 points is excellent. The point-rating system determines transparency of the results, develops independence and the ability to predict the result.

Creation and evaluation of tests and quizzes is carried out in Google forms, Yandex forms, on the Urayt platform and other complexes.

All course's components thematic focus, supporting material were prepared for each component, glossary, lectures, multi-level tests, workshops, multimedia technology can improve the didactic training of foreign language teachers with research competence and creativity and innovative teaching techniques.

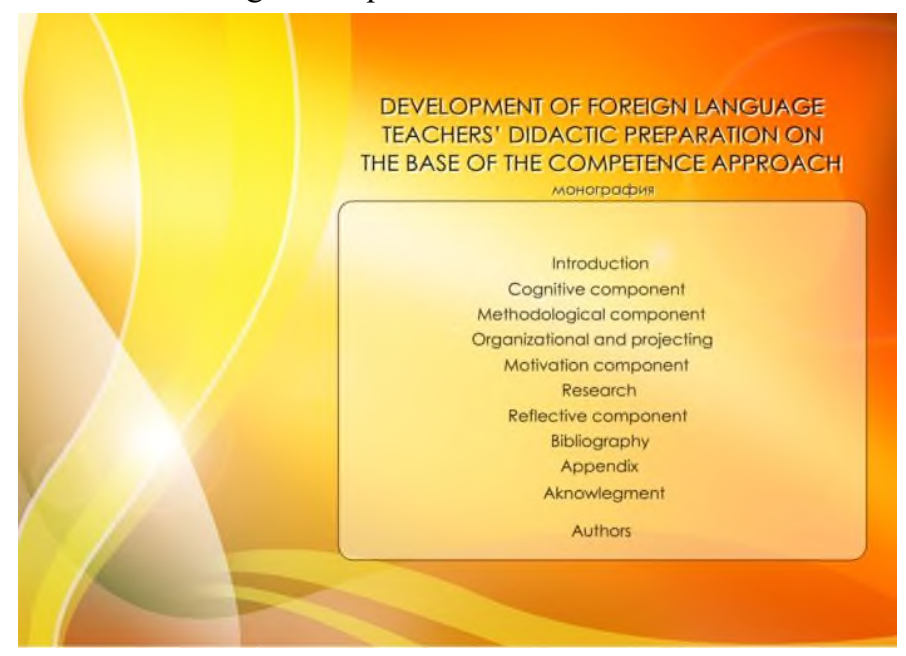

Fig. 3. Development of foreign language teachers' didactic preparation on the base of the competence approach.

The authors carried out work on tests preparation, including the preparation of pedagogical measuring materials (PMM) for assessing the formed students' competencies on the basis of a single portal http://iexam.ru. On the basis of the Test-Constructor module, tasks were prepared for conducting current and final control in the disciplines of the professional cycle. "Solvability maps" of the discipline were prepared, which made it possible to adjust the test questions. Testing was carried out on stationary and mobile devices.

\section{Conclusions}

Online training increases the capabilities of a teacher and students, increases motivational activity, including the use of new software products. It is necessary to update the content of the work programs and optimize the time spent in order to ensure sustainability (continuation). Teachers must create conditions, when "students with gadgets" want to study, starting with the most well-developed and favorite courses, gradually implementing them in the electronic educational space. 


\section{References}

1. L. Smetannikov, Development of Science teachers' training through the introduction of information modeling elements in the design of software tools for educational purposes (Moscow, 148, 2000)

2. K.L.Evelyn, W.P. Oliver, Computer Assisted Language Learning An Investigation on Some Design and Implementation 15, 31-39 (1987)

3. J.Higgins, Can Computers Teach? CALICO Journal 7, 23-27 (1983)

4. J.Higgins, T. Johns, Computer Languages Learning (Glasgow, 112, 1984)

5. "Educational equipment-pros" Educational equipment and visual AIDS for learning

6. L.A.Maksimenko, E.A.Tanygina, V.A. Kalyuzhin, Application of Autodesk software products for training students in the direction of "land Management and cadastre" Bulletin of the Siberian state University of geosystems and technologies 23, 1, 240-249 (2018)

7. G.M. Kodzhaspirova, K.V.Petrov, Technical training environments properties and methods of their use: the textbook for university learner (Moscow center "Academy", 180, 2011)

8. V.A.Vul, Electronic editions, St Petersburg, Publishing House, St Petersburg Institute of the press (2009)

9. V.A.Kalyuzhin, A.A.Ilyin, Complex competence-oriented tasks in the discipline "Metrology, standardization and certification in geodesy and cadastre", Economics of nature management, land management, Le-soustroystvo, real estate management "Interexpo GEO-Siberia 2019", Novosybirsk Sgugit, 2, 215-232 (2019)

10. Yu.V.Mitrofanova, Formation of individual experience of creative activity of students by means of new pedagogical technologies when studying the geography of their area Abstract for the degree of candidate of science, St Petersburg (2005)

11. E.A.Sankova, Formation of cartographic competence of University students by means of professionally-oriented teaching technology, Orel (2012)

12. L.A.Maksimenko, Modern methods of evaluating the independent work, Collection of materials of the International scientific and methodological conference, Novosibirsk, Sgugit 102-107 (2020)

13. I.R.Lazarenko, T.M. Saliy, I.M. Makarikhina, Using new generation e-books in the High School educational process, including Faculty of Teachers' Development, Middle - East Journal of Scientific Research, 15, 1155 - 1159 (2013) http://www idosi org/mejsr/mejsr15(8)13/14 pdf

14. V.Krivoruchko, A. Raissova, G. Yergazinova, B. Kazhmuratova, I.Makarikhina, Mobile-Assisted Learning as a Condition for Effective Development Engineering Students' Foreign Language Competence International Education Studies 8, 7, 65-69 http://www ccsenet org/journal/index php/ies/article/view/50559/27165 